\title{
Using the intervention mapping protocol to develop a community-based intervention for the prevention of childhood obesity in a multi-centre European project: the IDEFICS intervention
}

Vera Verbestel ${ }^{1 *}$, Stefaan De Henauw ${ }^{2}$, Lea Maes², Leen Haerens ${ }^{1,3}$, Staffan Mårild ${ }^{4}$, Gabriele Eiben ${ }^{5}$, Lauren Lissner ${ }^{5}$ , Luis A Moreno ${ }^{6}$, Natalia Lascorz Frauca ${ }^{6}$, Gianvincenzo Barba ${ }^{7}$, Éva Kovács $^{8}$, Kenn Konstabel ${ }^{9}$, Michael Tornaritis ${ }^{10}$, Katharina Gallois ${ }^{11}$, Holger Hassel ${ }^{11,12}$ and Ilse De Bourdeaudhuij ${ }^{1}$

\begin{abstract}
Background: The prevalence of childhood obesity has increased during the past decades and is now considered an urgent public health problem. Although stabilizing trends in obesity prevalence have been identified in parts of Europe, preventive efforts in children are still needed. Using the socio-ecological approach as the underlying theoretical perspective, the IDEFICS project aimed to develop, implement and evaluate a community-based intervention for the prevention of childhood obesity in eight European countries. The aim of the present manuscript was to describe the content and developmental process of the IDEFICS intervention.

Methods: The intervention mapping protocol (IMP) was used to develop the community-based intervention for the prevention of childhood obesity in 3 to 10 years old children. It is a theory- and evidence-based tool for the structured planning and development of health promotion programs that requires the completion of six different steps. These steps were elaborated by two coordinating centers and discussed with the other participating centers until agreement was reached. Focus group research was performed in all participating centers to provide an informed basis for intervention development.

Results: The application of the IMP resulted in an overall intervention framework with ten intervention modules targeting environmental and personal factors through the family, the school and the community. The summary results of the focus group research were used to inform the development of the overall intervention. The cultural adaptation of the overall intervention was realised by using country specific focus group results. The need for cultural adaptation was considered during the entire process to improve program adoption and implementation. A plan was developed to evaluate program effectiveness and quality of implementation.

Conclusions: The IDEFICS project developed a community-based intervention for the prevention of childhood obesity by using to the intervention mapping heuristic. The IDEFICS intervention consists of a general and standardized intervention framework that allows for cultural adaptation to make the intervention feasible and to enhance deliverability in all participating countries. The present manuscript demonstrates that the development of an intervention is a long process that needs to be done systematically. Time, human resources and finances need to be planned beforehand to make interventions evidence-based and culturally relevant.
\end{abstract}

\footnotetext{
* Correspondence: Vera.Verbestel@UGent.be

'Department of Movement and Sport Sciences, Ghent University,

Watersportlaan 2, Ghent 9000, Belgium

Full list of author information is available at the end of the article
} 


\section{Background}

The prevalence of overweight and obesity in Europe has increased during the past decades $[1,2]$ and is considered a significant public health problem [2]. This worrying trend has not only been evident among European adolescents and adults but has also been identified in children below the age of 10 [1-3]. Although the prevalence of childhood obesity is stabilizing in some European countries $[4,5]$, the prevalence is still alarming because childhood obesity is related with adverse health consequences [6] and tends to persist into adulthood $[7,8]$. As the prevalence of childhood obesity remains generally high, especially in groups with a lower socioeconomic status (SES) [5], preventive efforts in children are still needed.

Evidence already indicated that school-based interventions can be effective in the prevention of overweight but to date, the majority of childhood obesity prevention efforts described in the literature have been unsuccessful [9-11]. Furthermore, there is a growing recognition that childhood obesity should be prevented by using a global socio-ecological approach. According to the socio-ecological approach, effective behavioral change can be obtained by targeting the ecological environment of the child which includes the family, the school and the community at large and by targeting psychological, sociocultural, policy and physical environmental factors [12-15]. However, the use and evaluation of multilevel approaches in the prevention of childhood obesity is rare $[9,16]$. The IDEFICS (Identification and prevention of Dietary- and lifestyle-induced health EFfects In Children and infantS) project aims to counter the lack of an ecological approach in previous intervention-based research [17]. Therefore a main purpose of the IDEFICS project is to develop, implement and evaluate a community-based preventative intervention program in 2-10 year old children in eight different European countries (Belgium, Cyprus, Estonia, Germany, Hungary, Italy, Spain, Sweden) $[18,19]$.

Because the literature previously called for a structured and evidence-based development of intervention programs [20], the intervention mapping protocol (IMP) was used as the theoretical framework for the development of the IDEFICS intervention. The IMP is a problem- and theory-driven protocol that was especially developed to guide the design of evidence-based intervention programs [13]. It also recognizes the importance of a socio-ecological approach in behavioural change $[13,20]$ which was of particular importance in the present project. Furthermore, the IMP aids and necessitates the detailed description of intervention content which meets recent demands for more thorough reporting on what happens in interventionbased research [21].
The present paper will describe and inform program planners about the process of developing an intervention program in a multi-centre European project by using the intervention mapping heuristic.

\section{Methods}

The IDEFICS intervention has been developed according to the IMP. This protocol describes the process for developing theory- and evidence-based intervention programs [13] and consists of six different steps: 1) needs assessment, 2) formulation of change objectives, 3) selection of theory-based methods and practical strategies, 4) development of the intervention program, 5) development of an adoption and implementation plan, and 6) development of an evaluation design. This paper briefly explains the core processes of the protocol and a more comprehensive overview of the IMP can be found at http://interventionmapping.com.

Two out of the eight intervention centers were responsible for coordinating and developing the IDEFICS intervention (Ghent University and University of Gothenburg). Draft versions of the elaborated intervention mapping steps (excluding step 2 and 3) were discussed with the other intervention centers until agreement was reached. In total, 24 months were available for the development of the intervention. The process of developing an intervention in a multi-centre European project according to the intervention mapping heuristic within this timeframe is outlined in Table 1 and described in more detail below.

\section{Step 1: Needs assessment}

In the first step of the protocol, the health problem is analyzed, followed by a study of the related risk behaviours and its determinants [13]. The needs assessment of the present study was focused on the target group of the IDEFICS project (i.e. 3 to 10 years old children) and included an analysis of the literature on the determinants and correlates of childhood obesity, the role of predefined behavioral risk factors in the development of childhood obesity (i.e. physical activity, dietary behavior and stress) and its related determinants. Further, the literature reporting on effective interventions in the prevention of childhood obesity was analyzed. This literature analysis was done by the main coordinating center.

In addition, focus group interviews were conducted in all countries with children, parents of different socioeconomic backgrounds, teachers and community leaders to identify local barriers, difficulties and influencing factors of the predefined target behaviors. The focus group protocol was developed and coordinated across the intervention centers by the main coordinating centre and finalized together with all participating centers. A detailed description of the protocol can be found 
Table 1 Timeline of intervention development activities during the preparation phase of the project (September 2006 - August 2008)

\begin{tabular}{|c|c|c|}
\hline \multicolumn{3}{|c|}{ YEAR 1: SEPTEMBER 2006 - AUGUST 2007} \\
\hline SEP OCT NOV DEC & $\begin{array}{l}\text { JAN FEB MAR APR MAY JUN } \\
\text { JUL }\end{array}$ & $A \cup G$ \\
\hline $\begin{array}{l}\text { Literature review by the main coordinating centre } \\
\text { Development of focus group protocol by main coordination centre }\end{array}$ & $\begin{array}{l}\text { Conduction of focus groups in } \\
\text { all intervention centers } \\
\text { Elaboration of the Needs } \\
\text { Assessment (step 1) by the } \\
\text { coordinating intervention } \\
\text { centers }\end{array}$ & $\begin{array}{l}\text { FIRST face-to-face meeting with all } \\
\text { intervention centers: } \\
\text { - Agreement upon step } 1 \\
\text { - Brainstorming about the change } \\
\text { objectives (step 2), the selection of } \\
\text { theory-based methods and practical } \\
\text { strategies (step 3), the program } \\
\text { development (step 4) and the adoption } \\
\text { and implementation plan (step 5) }\end{array}$ \\
\hline
\end{tabular}

YEAR 2: SEPTEMBER 2007 - AUGUST 2008

\begin{tabular}{|c|c|c|c|c|}
\hline SEP OCT & NOV & DEC & JAN & FEB MAR APR MAY JUN JUL AUG \\
\hline $\begin{array}{l}\text { Elaboration } \\
\text { of step 2-5 } \\
\text { by the } \\
\text { coordinating } \\
\text { intervention } \\
\text { centers }\end{array}$ & $\begin{array}{l}\text { SECOND face-to-face meeting } \\
\text { with all intervention centers: } \\
\text { - Agreement upon step } 4 \text { and } 5 \\
\text { - Checking the conformity of the } \\
\text { intervention modules with the } \\
\text { focus groups results in all } \\
\text { intervention centers } \\
\text { Discussing the feasibility of } \\
\text { adoption and implementation of } \\
\text { the intervention in all } \\
\text { intervention centers }\end{array}$ & $\begin{array}{l}\text { Finalization of step } 4 \\
\text { and } 5 \text { by the } \\
\text { coordinating } \\
\text { intervention centers }\end{array}$ & $\begin{array}{l}\text { CENTRAL training } \\
\text { on intervention } \\
\text { activities: } \\
\text { - Fine tuning of } \\
\text { the intervention } \\
\text { between centers } \\
\text { - Discussion of } \\
\text { opportunities for } \\
\text { cultural } \\
\text { adaptation } \\
\text { Discussion of draft } \\
\text { version of process } \\
\text { evaluation } \\
\text { instruments }\end{array}$ & $\begin{array}{l}\text { Local training(s) in each intervention centre } \\
\text { Reporting the plans for cultural and local adaptation in } \\
\text { written form to the coordination centers } \\
\text { Preparation of local intervention adaptation and } \\
\text { implementation } \\
\text { Further development and agreement about process } \\
\text { evaluation instruments by e-mail and telephone } \\
\text { conferences }\end{array}$ \\
\hline
\end{tabular}

elsewhere [22,23]. A first face-to-face meeting with personnel from all intervention centers was held in August 2007 to discuss the results of the needs assessment (Table 1) and to agree upon the behavioral program objectives. This face-to-face meeting was also used to brainstorm about the subsequent intervention mapping steps.

\section{Step 2: Formulation of change objectives}

In the second step of the protocol, each program objective was subdivided into performance objectives. These objectives are the expected sub behaviours that have to be accomplished by the target group to achieve the program objective. By crossing the determinants with the performance objectives, the more general performance objectives were translated into very specific intervention objectives, i.e. the change objectives. Change objectives were formulated for each program objective and were formulated by the coordinating centres.

\section{Step 3: Selection of theory-based methods and practical strategies}

The third step of the IMP includes the identification and selection of theoretical methods considered to influence changes in the selected determinants [13]. During this selection process, the summary of theoretical methods provided by Bartholomew and colleagues [13] was used. In a next step, practical strategies had to be identified to put the theoretical methods into practice [13]. Special efforts were made to search for and select existing strategies that fitted with the theoretical methods and specific intervention objectives. The summary results of the focus groups were used to inform the selection of existing strategies and the development of new strategies. This intervention mapping step was elaborated by the coordinating centers.

\section{Step 4: Program development}

In this step of the IMP, the information from all previous steps was combined with the intervention program as the final result [13]. A proposal for the content of the IDEFICS intervention was made by the coordinating centers. This was discussed with all IDEFICS partners during a second face-to-face meeting in November 2007 (Table 1). During this meeting, attention was paid to the fact that the overall intervention and/or specific intervention components were in line with the focus group results in all centers. Additionally, the feasibility of adopting and implementing the program in all centers was discussed.

\section{Step 5: Adoption and implementation}

The focus of the fifth step of the protocol is the planning of program adoption and implementation, 
including the consideration of program sustainability [13]. This step of the protocol was supported and informed by the focus group results indicating that the IDEFICS intervention had to be flexible enough to deal with the variability in local circumstances between and within countries [22,23]. Agreement about the strategy for program adoption and implementation was reached during the second face-to-face meeting in November 2007 and finilised by the beginning of 2008 (Table 1). In January 2008, a central training was organised in one of the coordinating centers to finetune all intervention components between centres and to discuss opportunities for cultural and local adaptation. In the months after the central training, all intervention centres planned the adoption of the intervention by the local stakeholders. Plans for cultural and local adaptations made during these preparatory months, were reported in written form to the main coordination centre. In the months before the start of the intervention, all centres organised local training(s) for the research staff being responsible for the adoption of the IDEFICS intervention in the local community.

\section{Step 6: Evaluation design}

In the last step of the IMP, program planners develop a plan to evaluate the effectiveness and to assess the quality of intervention implementation [13]. In contrast to the sequence of intervention mapping steps, the evaluation design was already defined by the start of the European project.

The process evaluation was developed by the main coordinating center as soon as agreement about the intervention content was reached (November 2007). The development of the process evaluation instruments was based on the model of Saunders et al. [24]. During the central training in January 2008, draft versions of the process evaluation instruments were discussed with all intervention centers. Final agreement about the process evaluation instruments was reached through e-mail communication and telephone conferences (Table 1).

\section{Results}

\section{Step 1: Needs assessment}

The literature search revealed that socio-economic status (SES) is an important correlate of body weight $[25,26]$. Several studies found that children from a lower socio-economic background are at higher risk for the development of obesity [25,27]. Consequently, SES needs to be considered as an important factor in the prevention of childhood obesity. It was also concluded from the literature that specific physical activity, dietary and stress related behaviors are associated with the development of childhood obesity.
The needs assessment resulted in a selection of two key behaviors for each predefined behavior. These key behaviors were translated into six program objectives (Table 2): (1) increasing daily physical activity levels, (2) decreasing daily television (TV) viewing time, (3) increasing the consumption of fruit and vegetables, (4) increasing the consumption of water, (5) strengthening parent-child relationships and (6) establishing adequate sleep duration patterns. All program objectives (except for the second) were positively phrased to avoid negative associations to those objectives and to the overall IDEFICS intervention. The rationale for the selection of these program objectives is described below.

\section{Increasing daily physical activity levels and decreasing TV} viewing time

Physical activity and sedentary behavior are two components of energy expenditure that contribute to the development of childhood obesity $[28,29]$. Several studies demonstrated that higher levels of physical activity during early childhood are protective in developing body fat [30-34]. A recent literature review from Monasta and colleagues [35] reported that less than 30 minutes of daily physical activity at preschool age is associated with an increased risk for overweight and obesity

$\mathrm{TV}$ viewing is a sedentary behavior consistently being associated with the development of childhood obesity. The reduction of this behavior is suggested to be one of the more successful ways to prevent childhood obesity [28,36-38]. For example, Reilly et al. [38] found that watching more than eight hours TV per week at the age of three is independently related with the risk of obesity. The association between watching TV and childhood obesity is possibly mediated by an increased energy intake in children [28,36,37], underlining the need to target TV viewing as a sedentary risk behavior in the prevention of childhood obesity [37].

Increasing daily consumption of fruit, vegetables and water As large portions of energy-dense foods are found to be positively associated with obesity in early childhood [39], promoting low-energy dense foods might be a promising approach for the prevention of childhood obesity $[40,41]$. The review of Libuda and Kersting [42] summarized the available evidence on the positive association between childhood obesity development and sugar-

$\begin{aligned} & \text { Table } 2 \text { Specific program objectives of the IDEFICS } \\
& \text { intervention }\end{aligned}$
\begin{tabular}{ll}
\hline Physical activity & 1. Increasing daily physical activity levels \\
& 2. Decreasing daily TV viewing time \\
\hline Diet & 3. Increasing daily consumption of fruit and vegetables \\
& 4. Increasing daily consumption of water \\
\hline Stress & 5. Strengthening parent-child relationships \\
& 6. Establishing adequate sleep duration patterns \\
\hline
\end{tabular}


sweetened beverage consumption. Because of this association and the recommendation of the IMP to target health-promoting behaviors (i.e. the opposite of the risk behavior) [13], it was decided to replace sugar-sweetened beverages by a non-caloric alternative and to select water consumption as one of the dietary behaviors to be targeted by the IDEFICS intervention. This decision is supported by a recently conducted randomized controlled cluster trial demonstrating that the promotion of water consumption effectively prevents overweight in elementary school children [43]. At the time of conducting the needs assessment, no convincing evidence of other dietary risk factors of childhood obesity was available [39], however, the consumption of fruit and vegetables was selected as a second dietary related target behavior. This decision was based on the healthpromoting behavioral approach endorsed by the IMP and the finding that low-energy dense foods, such as fruit and vegetables, moderate energy intake in young children $[40,41,44]$.

\section{Strengthening parent-child relationships and establishing adequate sleep duration patterns}

There is currently a growing interest in the role of stress in the development of obesity $[45,46]$. So far, Koch and colleagues [47] found that children who are exposed to psychological stress in the family are more likely to be obese. Generally, the role of the family in childhood obesity is a growing field of interest $[48,49]$ and considered to be important for children's health [47]. The focus group research indicated that interaction and quality time with parents (playing, helping, stay home with the children and doing things together) is believed to reduce stress in children (unpublished IDEFICS data). Based on face-to-face discussions with the intervention centres, it was therefore decided to address stress in children by strengthening parent-child relationships as a fourth program objective.

Growing evidence also suggests that sleep duration is an important risk factor for the development of childhood obesity [35,38,50-53]. Several studies demonstrated that short sleep duration during childhood, i.e. less than 10 hours a day, is an independent risk factor for childhood obesity $[38,50,52]$.

\section{Step 2: Formulation of change objectives}

The six program objectives (Table 2) were subdivided into performance objectives. As an illustration, the performance objectives of the first program objective "Increasing daily physical activity levels" are presented in Table 3. These performance objectives were formulated based on the guidelines from the National Association for Sport and Physical Education which is currently the most widely used recommendation for physical activity in young children [54]. By crossing the performance objectives with the selected determinants, change objectives were formulated. As an example, the change objectives for the program objective about daily physical activity levels in relation to parental support and physical activity related practices are presented in Table 3.

\section{Step 3: Selection of theory-based methods and practical strategies}

Table 4 presents the methods that were selected for the development of the intervention. This table also

Table 3 Change objectives (i.e. specific intervention objectives) with the aim to increase children's daily activity levels

\begin{tabular}{|c|c|c|}
\hline \multirow[t]{2}{*}{ Performance objectives } & \multicolumn{2}{|l|}{ Determinants } \\
\hline & Parental support & Physical activity related policies \\
\hline $\begin{array}{l}\text { Children engage in structured physical activity } \\
\text { for at least } 60 \text { minutes a day }\end{array}$ & $\begin{array}{l}\text { Parents model physical activity in a } \\
\text { structured way } \\
\text { Parents provide opportunities for } \\
\text { participating in structured physical } \\
\text { activities }\end{array}$ & $\begin{array}{l}\text { The community and school setting provide opportunities } \\
\text { to be physically active in a structured way } \\
\text { The community and school setting organise physical } \\
\text { activities in a structured way }\end{array}$ \\
\hline $\begin{array}{l}\text { Children engage in unstructured physical } \\
\text { activity for at least } 60 \text { minutes and up to several } \\
\text { hour a day }\end{array}$ & $\begin{array}{l}\text { Parents model physical activity in an } \\
\text { unstructured way } \\
\text { Parents provide opportunities for } \\
\text { being physically active in an } \\
\text { unstructured way }\end{array}$ & $\begin{array}{l}\text { The community and school setting provide opportunities } \\
\text { to be physically active in an unstructured way } \\
\text { The community and school setting organise physical } \\
\text { activities in a unstructured way }\end{array}$ \\
\hline $\begin{array}{l}\text { Children are not sedentary for more than } 60 \\
\text { minutes at a time except when sleeping }\end{array}$ & $\begin{array}{l}\text { Parents reduce the child's exposure } \\
\text { to triggers of sedentary behaviour } \\
\text { Parents set rules regarding time spent } \\
\text { in sedentary activities }\end{array}$ & $\begin{array}{l}\text { The community and school setting provide alternatives for } \\
\text { sedentary behaviours }\end{array}$ \\
\hline $\begin{array}{l}\text { Children develop competence in movement } \\
\text { skills }\end{array}$ & $\begin{array}{l}\text { Parents provide opportunities to } \\
\text { develop competence in movement } \\
\text { skills }\end{array}$ & $\begin{array}{l}\text { The community and school setting provide opportunities } \\
\text { for movement experiences to build on children's } \\
\text { movement skills }\end{array}$ \\
\hline $\begin{array}{l}\text { Children become familiar with different kinds of } \\
\text { physical activities }\end{array}$ & $\begin{array}{l}\text { Parents provide opportunities for } \\
\text { trying different kinds of physical } \\
\text { activities }\end{array}$ & $\begin{array}{l}\text { The community and school setting provide opportunities } \\
\text { to try out different kinds of physical activities }\end{array}$ \\
\hline
\end{tabular}


Table 4 Overview of the selected theoretical methods and practical strategies used in the IDEFICS intervention

\begin{tabular}{|c|c|c|}
\hline $\begin{array}{l}\text { Level of the } \\
\text { intervention }\end{array}$ & Methods & Related strategies \\
\hline \multirow[t]{4}{*}{$\begin{array}{l}\text { Community } \\
\text { level }\end{array}$} & Forming coalitions & $\begin{array}{l}\text { Development of an organisational structure at the community level } \\
\text { stimulate collaboration across different agenda's; technical } \\
\text { assistance on action and strategic planning (module 1) }\end{array}$ \\
\hline & Policy and media advocacy & $\begin{array}{l}\text { Placing the topic on the political agenda; sharing resources; } \\
\text { increasing public awareness (module 2) }\end{array}$ \\
\hline & & Changes in the environment (module 3 ) \\
\hline & Facilitation & \\
\hline \multirow[t]{2}{*}{ School level } & Forming coalitions & $\begin{array}{l}\text { Development of an organisational structure at the school level; } \\
\text { stimulate collaboration across different agenda's; technical } \\
\text { assistance on action and strategic planning (module 4) }\end{array}$ \\
\hline & Facilitation & Changes in the environment (module 6, 7,8 and 9) \\
\hline Class level & $\begin{array}{l}\text { Alternation of perception (altering the perceptions of pros and } \\
\text { cons of the desired behaviour so that children give preference } \\
\text { to the desired behaviour) } \\
\text { Reinforcement (providing reinforces (e.g. incentives) for the } \\
\text { performance of the desired behaviour) } \\
\text { Implementation intentions (defining specific plans of action, } \\
\text { which specify exactly when (time), where (place) and how } \\
\text { (response) to behave in future situations) } \\
\text { Goal setting (setting reasonable and challenging goals, goals } \\
\text { that are difficult but available within the individual's skill level) } \\
\text { Modelling with guided enactment (behavioural change by } \\
\text { observing and doing, supported by feedback and rewards) }\end{array}$ & $\begin{array}{l}\text { Classroom and homework related activities (module 5) } \\
\text { For example: } \\
\text { - practical classroom activities (e.g. tasting games, active } \\
\text { movement breaks) } \\
\text { - theoretical classroom activities (e.g. teaching children how to set } \\
\text { goals) } \\
\text { - diaries (registering of the progress of a specific behaviour and } \\
\text { reinforcement of the desired behaviour) } \\
\text { - creating and evaluating an accomplishment plan for the desired } \\
\text { behaviour (children taking home their behavioural goals set during } \\
\text { the theoretical lesson and trying to realise their goals with their } \\
\text { parents) }\end{array}$ \\
\hline
\end{tabular}

Family level Alternation of perception

Modelling with guided enactment

Persuasive communication
Homework related activities (module 5)

Homework related activities (module 5)

Homework related activities (module 5)

Educational folders and posters (module 10) describes how the theoretical methods were translated into practical strategies and how these relate to the levels of the intervention. Furthermore, Table 5 shows how the focus group results informed the selection and design of practical strategies.

\section{Step 4: Program development}

Step 4 of the protocol resulted in a final intervention framework considered for implementation in eight participating centers. Behavioral change at the individual level was targeted through the development of intervention modules at the level of the community, the schools (including kindergartens and primary schools) and the family. An overview of the intervention at these levels and the related modules and their respective timing can be found in Table 6. A full description of the IDEFICS intervention modules and centrally provided intervention materials will be made available on the IDEFICS website (http://www.idefics.eu). Information on how the summary results of the focus groups informed the development of the intervention program is presented in Table 5.

The intervention at the community level consisted of three intervention modules (module 1 to 3 ). Module 1 aimed at the establishment of a "community platform" which can be considered as a working group in which all local and relevant community members (local municipality, social services and welfare sector, private actors) had to be represented. Special emphasis was placed on the inclusion of community members having access to low SES and/or migration groups. The community platform was responsible for the implementation of all other modules at the community level (module 2 and 3 ). Module 2 consisted of the execution of a long term multimedia and public relations campaign to make the community aware of the intervention and the key behaviours targeted by the intervention. Module 3 involved the development of a short and a long term perspective for the prevention of childhood obesity to establish and induce environmental and policy interventions in the community. The short term perspective required that the community platform developed and implemented a list of obesity preventive actions within the timeframe of the IDEFICS adoption period, i.e. the first year of the intervention (year 3 of the project from September 2008 till August 2009). The long term perspective of the IDEFICS intervention required the development of a list of 
Table 5 Association between the focus groups results, the final content of the IDEFICS intervention and the intervention mapping steps

\begin{tabular}{ll}
\hline Focus group result(s) & Objective/strategy \\
\hline $\begin{array}{l}\text { Children receive inconsistent messages } \\
\text { from family and school (regarding rules and }\end{array}$ & $\begin{array}{l}\text { Creating and enhancing uniformity of } \\
\text { availability of food) }\end{array}$ \\
& - Involving parents in environmental and \\
& policy changes at the school level \\
& - Creating a school environment in which \\
& healthy eating behaviours are the easiest \\
& choice \\
& - Involving the schools in the community \\
& platform to trigger collaboration between \\
& schools in the same community \\
& - Learning parents how to create a home \\
& environment in which healthy eating \\
& behaviours are the easiest choice
\end{tabular}

Interaction and quality time with parents (playing, helping, stay home with the children, doing things together ...) is believed to reduce stress in children

\section{Creating a program objective for the predefined behaviour "stress and relaxation"}

Content IDEFICS intervention

Intervention mapping step(s)

Module 4: Establishment of the school working groups Module 8: Environmental and policy changes related to water consumption

Module 9: Environmental and policy changes related to fruit and vegetable consumption Module 1: Establishment of the community platform

Module 10: Educational materials for parents providing strategies to create health promoting family environments

The predefined behaviour was translated into "Strengthening parent-child relationships"

Step 1 (Needs assessment) Step 3 (Selection of theory-based methods and practical strategies) Step 4 (Program development)
Differences in overall focus group results were larger within countries than between countries.
School related policies as a barrier for healthy eating at school (mentioned by the parents)

\begin{abstract}
Creating a structure that enables adaptation of an overall intervention framework within countries and between countries
\end{abstract}

Module 1: Establishment of the community platform Module 4: Establishment of the school working groups

Module 8: Environmental and policy changes related to water consumption

Module 9: Environmental and policy changes related to fruit and vegetable consumption Module 4: Establishment of the school working groups

Only the Belgian and Spanish children mentioned receiving lessons about healthy eating.
Creating a school environment in which healthy eating behaviours are the easiest choice

Involving parents in environmental and policy changes at the school level communication about food policy to the parents.
Providing ready to use nutrition education Module 5: Integration of the key lessons that can easily be incorporated into behaviours in the classroom the classroom curriculum, stimulate teachers activities and providing related

Step $1-3$ to daily promote healthy eating. homework activities (curriculumbased)

Parents perceive the schools as an important setting for the promotion of healthy eating and physical activity. Parents assigned the main responsibilities for healthy eating and physical activity promotion outside the family context.
Raising awareness among parents about their own role in promoting healthy eating and facilitate their in their ability to create health promoting family environments Creating a school environment in which healthy eating behaviours are the easiest choice

Creating an activity promoting school environment
Module 10: Educational materials for parents providing strategies to create health promoting family environments Module 8: Environmental and policy changes related to water consumption

Module 9: Environmental and policy changes related to fruit and vegetable consumption Module 6: Environmental changes related to physical activity: the active playground Module 7: Health related physical education curricula

\begin{tabular}{ll}
\hline Importance of taste for children's food & $\begin{array}{l}\text { Integrating tasting activities in the } \\
\text { classroom activities }\end{array}$ \\
preferences. &
\end{tabular}
classroom activities

\begin{tabular}{|c|c|}
\hline $\begin{array}{l}\text { Module 5: Integration of the key } \\
\text { behaviours in the classroom } \\
\text { activities and providing related } \\
\text { homework activities (curriculum- } \\
\text { based) }\end{array}$ & Step 1 - 3 \\
\hline $\begin{array}{l}\text { Module 5: Integration of the key } \\
\text { behaviours in the classroom } \\
\text { activities and providing related } \\
\text { homework activities (curriculum- } \\
\text { based) }\end{array}$ & Step 1 - 3 \\
\hline
\end{tabular}

\begin{tabular}{|c|c|c|}
\hline $\begin{array}{l}\text { Peers are perceived to influence the } \\
\text { preferences for certain food items. }\end{array}$ & $\begin{array}{l}\text { Stimulating the eating of healthy products } \\
\text { in group, stimulate teachers to be a role } \\
\text { model }\end{array}$ & $\begin{array}{l}\text { Module 5: Integration of the key } \\
\text { behaviours in the classroom } \\
\text { activities and providing related } \\
\text { homework activities (curriculum- } \\
\text { based) }\end{array}$ \\
\hline
\end{tabular}


Table 5 Association between the focus groups results, the final content of the IDEFICS intervention and the intervention mapping steps (Continued)

Media, free booklets and magazines, pamphlets and the food pyramid were channels through which parents receive information regarding healthy eating/living. Controversial opinions were assessed regarding the role of media and television (these channels are perceived to distribute contradictory and less reliable information)

Time spent outside is perceived to be dependent of opportunities to be physically active and neighbourhood safety (e.g. traffic, teenage gangs) physical activities offered for preschoolers.
Using the channels mentioned during the focus groups. Making a distinction between the intervention campaign and less reliable or contradictory information provided by certain media by using the IDEFICS logo on all documents.
Stimulating community members to

negotiate for larger scale actions that increase and improve the opportunities to be physically active (e.g. increasing the number of playgrounds and parks, providing age appropriate recreation areas) and negotiate for the improvement of neighbourhood safety.

Stimulating schools to include structured physical activities in preschoolers' weekly/ daily program.

Informing parents about the existing facilities and opportunities and stimulating them to provide these opportunities to their children (e.g. sports club)

Stimulating community member to negotiate for an adequate offer of structured physical activities for preschoolers in the community
Module 2:Long term multimedia Step 1 - 3 and public relations campaign

Stimulating community leaders to negotiate Module 3: Short and a long term for opportunities to participate in low-cost perspective for the prevention of activities and the possibilities for reductions childhood obesity developed by or lower prices for low SES families with local community members children.

(SES) mentioned that organized activities are often too expensive.
Module 1: Establishment of the Step 1 - 3

community platform

Module 3: Short and a long term perspective for the prevention of childhood obesity developed by local community members

Module 7: Health related physical Step 1 - 3 education curricula

Module 10: Educational materials for parents providing strategies to create health promoting family environments

Module 3: Short and a long term childhood obesity developed by local community members perspective for the prevention of
Providing physical education teachers with physical activity promoting didactic guidelines to increase physical activity

Parents had the perception that special physical education teachers are better role models and more often recognize the health promoting role of physical education than regular classroom teachers.

Social support by parents or friends was mentioned as a factor that influences the time playing outside.

\author{
Informing parents about the importance of Module 10: Educational materials Step 1 - 3 \\ their role in stimulating their child to be \\ physically active. \\ create health promoting family \\ environments
}

Module 7: Health related physical Step 1 - 3 education curricula obesity preventive actions that were not feasible to be accomplished during the adoption period and/or the stated time-limits of the project, mostly for reasons that relate to the time that is realistically required for integrating such actions in the policy implementation plans of communities. However, the community platform was asked to start advocating for the actions defined as part of the long term perspective. Table 7 presents a noncomprehensive list of possible obesity preventive actions that could be taken by the stakeholders of the community platform as part of the short and long term perspective.

The intervention at the school level consisted of 6 intervention modules (module 4 to 9). Module 4 aimed to establish a school working group in all local participating schools. The school working groups were considered to represent the school and parents' perspective on the intervention program and to provide insight in the realities of working with schools. Therefore, the working groups had to include at least one or more representatives of the school board, several teachers and one or more parent representatives. The school working groups were responsible for the implementation of all other intervention modules at the school level (module 5 to 9). Module 5 consisted of a curriculum-based intervention integrating the key behaviours in the classroom activities. To do so, every participating teacher had to organise eight "Healthy Weeks" during the school year. The timing and initially planned sequence of the Healthy Weeks is shown in Table 6. In each healthy week a specific key behaviour related to nutrition or physical activity was handled and homework was provided to increase involvement of parents. Module 6 focused on environmental changes related to physical 
Table 6 Overview and timing of the IDEFICS intervention modules

\begin{tabular}{|c|c|c|c|c|c|c|c|c|c|c|}
\hline & \multicolumn{3}{|c|}{ COMMUNITY } & \multicolumn{6}{|c|}{ SCHOOL } & \multirow{2}{*}{$\begin{array}{c}\text { FAMILY } \\
\text { Module } 10\end{array}$} \\
\hline & Module 1 & $\begin{array}{c}\text { Module } \\
2\end{array}$ & $\begin{array}{c}\text { Module } \\
3\end{array}$ & Module 4 & Module 5 & $\begin{array}{c}\text { Module } \\
\quad 6\end{array}$ & Module 7 & $\begin{array}{c}\text { Module } \\
8\end{array}$ & $\begin{array}{c}\text { Module } \\
9\end{array}$ & \\
\hline \multicolumn{11}{|c|}{ Year 2 of the project (last 7 months of the preparation phase; 2008) } \\
\hline FEB & $\begin{array}{c}\text { Establishment } \\
\mathrm{CP}\end{array}$ & \multicolumn{2}{|c|}{ Preparation by CP } & & & & & & & \\
\hline MAR & $\begin{array}{l}\text { Establishment } \\
\mathrm{CP}\end{array}$ & \multicolumn{2}{|c|}{ Preparation by CP } & & & & & & & \\
\hline APR & $\begin{array}{c}\text { Establishment } \\
\text { CP }\end{array}$ & \multicolumn{2}{|c|}{ Preparation by CP } & $\begin{array}{l}\text { Establishment } \\
\text { SWG }\end{array}$ & & .. Pre & aration by S & & & \\
\hline MAY & $\begin{array}{c}\text { Establishment } \\
\mathrm{CP}\end{array}$ & \multicolumn{2}{|c|}{ Preparation by CP } & $\begin{array}{l}\text { Establishment } \\
\text { SWG }\end{array}$ & & ...Pre & aration by S & G & $\ldots \ldots$ & \\
\hline$J U N$ & & \multicolumn{2}{|c|}{ Preparation by CP } & $\begin{array}{l}\text { Establishment } \\
\text { SWG }\end{array}$ & $\cdots$ & ....Pre & aration by S & G. .... & $\ldots+\cdots$ & \\
\hline$J U L$ & & \multicolumn{2}{|c|}{ Preparation by CP } & $\begin{array}{l}\text { Establishment } \\
\text { SWG }\end{array}$ & & ...Pre & aration by $\mathrm{S}$ & G. . . . & & \\
\hline AUG & & \multicolumn{2}{|c|}{ Preparation by CP } & $\begin{array}{l}\text { Establishment } \\
\text { SWG }\end{array}$ & & ....Pre & aration by S & G...... & $\ldots \ldots$ & \\
\hline \multicolumn{11}{|c|}{ Year 3 of the project (Intervention adoption phase; 2008 - 2009) - Implementation of the modules by: } \\
\hline SEP & & $\mathrm{CP}$ & $\mathrm{CP}$ & & & SWG & $\begin{array}{c}\text { (PE) } \\
\text { teachers }\end{array}$ & SWG & SWG & \\
\hline $\mathrm{OCT}$ & & $\mathrm{CP}$ & $\mathrm{CP}$ & & $\begin{array}{l}\text { Teachers } \\
\text { (PA) }\end{array}$ & SWG & $\begin{array}{c}\text { (PE) } \\
\text { teachers }\end{array}$ & SWG & SWG & $\begin{array}{c}\text { CP and/or SWG } \\
\text { (PA) }\end{array}$ \\
\hline NOV & & $\mathrm{CP}$ & $\mathrm{CP}$ & & $\begin{array}{l}\text { Teachers } \\
(\mathrm{FG})\end{array}$ & SWG & $\begin{array}{c}\text { (PE) } \\
\text { teachers }\end{array}$ & SWG & SWG & $\begin{array}{c}\text { CP and/or SWG } \\
(\mathrm{FG})\end{array}$ \\
\hline DEC & & $\mathrm{CP}$ & $\mathrm{CP}$ & & $\begin{array}{l}\text { Teachers } \\
\text { (TV) }\end{array}$ & SWG & $\begin{array}{c}\text { (PE) } \\
\text { teachers }\end{array}$ & SWG & SWG & $\begin{array}{c}\text { CP and/or SWG } \\
\text { (TV) }\end{array}$ \\
\hline JAN & & $\mathrm{CP}$ & $C P$ & & $\begin{array}{l}\text { Teachers } \\
\text { (W) }\end{array}$ & SWG & $\begin{array}{c}\text { (PE) } \\
\text { teachers }\end{array}$ & SWG & SWG & $\begin{array}{c}\text { CP and/or SWG } \\
\text { (W) }\end{array}$ \\
\hline FEB & & $\mathrm{CP}$ & $C P$ & & $\begin{array}{l}\text { Teachers } \\
\text { (PA) }\end{array}$ & SWG & $\begin{array}{c}\text { (PE) } \\
\text { teachers }\end{array}$ & SWG & SWG & $\begin{array}{c}\text { CP and/or SWG } \\
(P A)\end{array}$ \\
\hline MAR & & $\mathrm{CP}$ & $\mathrm{CP}$ & & $\begin{array}{c}\text { Teachers } \\
(\mathrm{FG})\end{array}$ & SWG & $\begin{array}{c}\text { (PE) } \\
\text { teachers }\end{array}$ & SWG & SWG & $\begin{array}{c}\text { CP and/or SWG } \\
(\mathrm{FG})\end{array}$ \\
\hline APR & & $\mathrm{CP}$ & $C P$ & & $\begin{array}{l}\text { Teachers } \\
\text { (TV) }\end{array}$ & SWG & $\begin{array}{c}\text { (PE) } \\
\text { teachers }\end{array}$ & SWG & SWG & $\begin{array}{c}\text { CP and/or SWG } \\
\text { (TV) }\end{array}$ \\
\hline MAY & & $\mathrm{CP}$ & $\mathrm{CP}$ & & $\begin{array}{l}\text { Teachers } \\
\text { (W) }\end{array}$ & SWG & $\begin{array}{c}\text { (PE) } \\
\text { teachers }\end{array}$ & SWG & SWG & $\begin{array}{l}\text { CP and/or SWG } \\
\text { (W) }\end{array}$ \\
\hline JUN & & $C P$ & $C P$ & & $\begin{array}{l}\text { Teachers } \\
\text { (SP) }\end{array}$ & SWG & $\begin{array}{c}\text { (PE) } \\
\text { teachers }\end{array}$ & SWG & SWG & $\begin{array}{c}\text { CP and/or SWG } \\
\text { (SP) }\end{array}$ \\
\hline JUL & & $\mathrm{CP}$ & $\mathrm{CP}$ & & & & & & & \\
\hline$\overline{A U G}$ & & $\mathrm{CP}$ & $\mathrm{CP}$ & & & & & & & \\
\hline
\end{tabular}

Modules: 1) Establishment of the community platform; 2) Long term multimedia and public relations campaign; 3) Short and a long term perspective for the prevention of childhood obesity developed by local community members; 4) Establishment of the school working groups; 5) Integration of the key behaviours in the classroom activities and providing related homework activities; 6) Environmental changes related to physical activity: the active playground; 7) Health related physical education curricula; 8) Environmental and policy changes related to water consumption; 9) Environmental and policy changes related to fruit and vegetable consumption; 10) Educational materials for parents providing strategies to create health promoting family environments

Implementers: $C P=$ community platform; SWG = school working group; (PE) teachers = (physical education) teachers

Topics "Healthy Weeks": PA = physical activity; FG = fruit and vegetable consumption; TV = television viewing; $W=$ water consumption; $S P=$ sleep duration

activity. For this module, school working groups were invited to create an active playground by providing attractive play tools (e.g. balls, ropes, small bikes) and/or by changing the physical design of the playground (e.g. hopscotch, soccer goal posts, basketball hoops). Module 7 aimed at reaching high(er) activity levels during physical education classes and increasing physical activity levels during the time that children spent in the classroom by providing physical education teachers with practical guidelines. Module 8 and 9 focused on environmental and policy changes related to water and fruit and vegetable consumption respectively. For these intervention modules, school working groups were requested to create a supportive school environment by inducing 
Table 7 Examples of possible actions that could be undertaken by the stakeholders of the community platform (module 3)

\begin{tabular}{|c|c|}
\hline $\begin{array}{l}\text { Possible stakeholders of the community } \\
\text { platform }\end{array}$ & Examples of possible actions \\
\hline $\begin{array}{l}\text { Local municipality (public health authorities) } \\
\text { and local politicians }\end{array}$ & $\begin{array}{l}\text { - Contribute to national obesity prevention plans } \\
\text { - Ensure that all young people have access to youth sports and recreation programs } \\
\text { - Promote alternatives for play such as involvement in local organizations (structured activities for } \\
\text { children in safe environment for minimal cost) } \\
\text { - Support and encourage the development of safe routes in the municipality (especially the routes to } \\
\text { schools): include sidewalks/footpaths on all new roads and upgrade the existing roads } \\
\text { - Taking vans with physical activity equipment into neighbourhoods that do not have access to } \\
\text { physical activity facilities. }\end{array}$ \\
\hline $\begin{array}{l}\text { Private sector (food companies, grocery } \\
\text { stores) }\end{array}$ & $\begin{array}{l}\text { - Organisation of shopping tours, grocery taste tests, cooking demonstrations, nutrition labelling } \\
\text { - Promote water and healthy food products like fruit and vegetables } \\
\text { - Provide easy recipes with fruit and/or vegetables that are typical for a certain season, provide ideas } \\
\text { to drink water in several ways (e.g. with a leaflet of mint, with pieces of apple, ...), provide and } \\
\text { promote healthy food, e.g. quality fruits and vegetables } \\
\text { - Provide healthy options on children's menus }\end{array}$ \\
\hline Working groups of the schools/kindergartens & $\begin{array}{l}\text { - Organise extracurricular physical activity programs } \\
\text { - Promote physical activity by disseminating information about community-based sports and recreation } \\
\text { programs and help these programs to gain access to school facilities outside of school hours } \\
\text { - Enable more after-school care programs to provide regular opportunities for active, physical play } \\
\text { - Remove vending machines, particularly soft-drink machines } \\
\text { - School pricing incentives that favour low- over high-energy density foods } \\
\text { - Promote active commuting to schools (e.g. mapping of safe routes to school, walk/bicycle to school } \\
\text { days, walking school buses, bicycle trains) }\end{array}$ \\
\hline Sport and youth organizations & $\begin{array}{l}\text { - Provide and promote free water during the activities } \\
\text { - Stimulate the children not to bring sugar sweetened beverages } \\
\text { - Stimulate the children to bring fruit and/or vegetables instead of unhealthy snacks } \\
\text { - Organise activities in which the family of the children can participate (family events) }\end{array}$ \\
\hline Health care providers & $\begin{array}{l}\text { - Provide assessment, counselling and referral on physical activity, diet, stress, coping and relaxation as } \\
\text { part of health care } \\
\text { - Encourage parents to be role models for their children in the field of physical activity, diet, stress, } \\
\text { coping and relaxation }\end{array}$ \\
\hline
\end{tabular}

changes in the school environment and policy (e.g. providing the opportunity to drink water in class, making fruit and vegetables available and accessible in the class room or the school canteen).

The intervention at the family level (module 10) consisted of educational materials (posters and flyers) for parents providing them with strategies to remove barriers and facilitate them in their ability to create health promoting family environments.

\section{Step 5: Adoption and implementation}

As the IDEFICS intervention had to be able to deal with the variability in local circumstances between and within countries [22,23], an overall intervention framework with ten different modules was developed, including opportunities for cultural adaptation. The primary aim of integrating opportunities for cultural adaptation was to implement a culturally equivalent version of the overall intervention framework in all participating countries [55]. Opportunities for cultural adaptation were included in the overall intervention framework by the concept of the community platform (module 1 ) and the school working groups (module 4). These were considered to adapt the overall intervention program to the local and cultural needs within the community and the schools. Examples of how the intervention was culturally adapted in different countries are shown in Table 8 .

During the first year of the IDEFICS intervention, the intervention was coordinated and supported by the IDEFICS project itself. Therefore, a member of the research staff was appointed as the local "intervention program manager" (IPM) in each participating country. The IPM was responsible for establishing, organizing and coordinating the community platform (module 1 ) and the school working groups in all participating schools (module 4). The IPM could be a staff member that was involved in the developmental process at the central level, another staff member (not involved at the central level) or a representative person in the local community. If the IPM was not involved in the developmental process at the central level, he/she was informed during local trainings organized within each intervention centre (Table 1).

The community platform was responsible for the local development and implementation of the intervention modules at community (module 2 and 3 ) and family level (module 10). The school working groups were 
Table 8 Examples of cultural adaptations made to the overall intervention framework

\begin{tabular}{ll}
\hline Intervention modules & Examples of cultural adaptations \\
\hline Module 1: Establishment of the community platform & - Use of existing community platforms instead of creating a new one (e.g. \\
& Sweden): the Public Health council and the Child- and Youth steering council were \\
platforms already meeting five to six times a year. These platforms cooperated to & act as the community platform of the IDEFICS intervention. \\
& - No establishment of a community platform (e.g. Italy): no community platform \\
& was created because of the involvement of four different municipalities in the \\
& intervention region. To overcome this problem, the school working groups (one for \\
& each municipality) were extended with one (or more) representative(s) of the \\
& municipality administration (acting on behalf of the Major of the town) and with a \\
& representative of the National Health Service (a community pediatrician). One \\
& school working group was established in each community because the \\
& municipalities involved in the IDEFICS intervention were small towns with one or \\
& two primary (plus kindergarten) schools that therefore include the whole \\
population living in the area.
\end{tabular}

Module 4: Establishment of the school working groups

- Creation of school working groups at the level of the school boards (e.g. Belgium): several schools can be authorized under the same school board. These schools are mostly located at different places in the community. All schools of the same board, have to follow the same school policy which means that they are not independently operating. Therefore, it was not possible to create a school working group in each school and school working groups were created at the level of the school boards. This means that in the Belgian intervention region, 11 school working groups were created representing 21 schools in total.

- No establishment of school working groups (Cyprus): as the school system is strictly regulated by the Ministry of education, no changes can be made in schools without going through the Ministry. Therefore, the intervention at school level was not independently implemented from the intervention at the community level. No school working groups were created but they were integrated in the community platform. The platform consists of two main parts: a first part includes the local authorities and stakeholders and a second part includes the authorities of each school. The first part of the platform is taking the decisions while the second part is responsible for the implementation.

Module 5: Integration of the key behaviours in the classroom activities and providing related homework activities

- Adaptations to the timing of the healthy weeks because of a different timing of (summer) holidays across European countries (e.g. start of the healthy weeks in September in Sweden and in October in Belgium).

- Adaptation to the sequence of the healthy weeks based on local situations (e.g. Sweden): the healthy week about sleep duration was removed from June to September because an average day in June has about 20 hours of daylight which makes it complicate to talk about sleep duration.

responsible for the development and implementation of the intervention program at the school level (module 5 to 9). The establishment of the community platform and school working groups varied between countries. In some countries, a community platform and/or school working groups were already in place and therefore could be used and further elaborated according to the IDEFICS format, while other countries had to compile a new platform and/or create new school working groups. The process of establishing new school working groups within the foreseen time-frame (Table 6) was perceived more feasible by the countries than establishing a community platform. The ability of the school working groups to act as implementers of the intervention seemed to be realistic as school working groups seemed to be a commonly used strategy in schools across Europe. The capacity of the platform to act as implementers of the modules at community level varied across countries and was more successful in countries where an existing platform was already available.
The establishment of the community platform and the school working groups enabled adaptation to the local culture and circumstances and ensured the adoption and implementation of the overall intervention framework at all levels of the intervention. However, it has to be noted that the cultural adaptation of the IDEFICS intervention was only allowed at the level of the strategies. For example, the community platform (module 1) was expected to elaborate local initiatives contributing to the prevention of childhood obesity (module 3). Possible actions were centrally provided (Table 7) but the local community platform was allowed to search for and to elaborate other initiatives, as long as the initiatives still fitted with the objectives of the respective module. No central approval was required for the initiatives proposed by the local community platforms. However, the IPM was expected to coordinate and scientifically supervise the community platform. This means that the quality of the intervention was regulated at the level of the countries. 


\section{Step 6: Evaluation design}

A quasi-experimental study design was developed to evaluate the effectiveness of the IDEFICS intervention. In each of the eight intervention centers, the intervention region was matched with a comparable control region. Data of about 1000 children (aged 3-10 years old) were collected in each region, comprising data of 2000 children in each country. Data were simultaneously collected in all centers at baseline (T0), 24 months later (T1) and at follow-up (T2). The IDEFICS intervention started in September 2008 and ended in August 2010. The intervention was divided into three stages of program use, referring to the classical phasing of establishing interventions: adoption phase, implementation phase and dissemination phase [13]. The adoption phase was characterized by continuous support and scientific supervision from IDEFICS staff in each country. This input gradually decreased throughout the stages of program use. The effectiveness of the IDEFICS intervention will be evaluated with regard to body mass index, anthropometric measures (primary outcomes) and the behaviors related to the specific program objectives (secondary outcomes). Details about general design, participants, field measurements and related protocols have already been described elsewhere $[18,19,56]$. The effectiveness of the intervention will also be evaluated with respect to the stages of program use. More specifically, the effectiveness of the adoption phase will be executed by analyzing changes in the outcomes between $\mathrm{T} 0$ and $\mathrm{T} 1$ in the intervention and control communities and the effectiveness of the implementation phase by analyzing changes in outcomes between T1 and T2. Process evaluation questionnaires were developed for the community members of the community platform, school working groups, teachers and parents. The collection of process evaluation data was synchronized with the survey activities in both control and intervention regions.

\section{Discussion}

The present paper describes the developmental process, content and evaluation design of the IDEFICS intervention. This paper is unique as this process occurred in a multi-centre European context including eight different countries. Furthermore, the IDEFICS intervention focused on six different behaviors through the involvement of the community, the schools and the family which enriches the current literature on interventionbased research aiming at the prevention of childhood obesity. The IMP was used as the conceptual framework for developing the IDEFICS intervention. Due to the foreseen timeframe and the multi-level and multi-behavioral approach of the European project, the protocol was not strictly followed and was reduced in its complexity. This means that the matrices of change objectives were only created at the individual level instead of creating matrices for each level of intervention planning (individual, school, family and the community). However, the roles identified at each ecological level were not neglected but were integrated in the formulation of the change objectives. Despite this reduction in complexity, we believe that the IDEFICS intervention still matches the systematic and evidencebased approach. Though, the development of the intervention was perceived as a time-consuming process. The use of the IMP requires scientific staff, budget and time, and this should be taken into consideration when applying for funds for intervention development. Even if less complex interventions (e.g. fewer behaviors and/or levels) need to be developed, time, financial and human resources should be planned to allow for a systematic and evidence-based development of an intervention.

The external validity of the IDEFICS intervention was an important issue throughout the entire developmental process. As experienced during face-to-face meetings in the present project, this increased the tendency of taking into account very specific and country dependent information during the development of the overall intervention framework. To avoid this tendency, we consider a central coordination as fundamental but acknowledge the importance of continuous contact and consultation with all cooperating centers to guarantee the opportunities and feasibility of local and cultural adaptation.

The focus groups results were used to inform the development of the intervention. However, it was a challenge to find a balance between general information, relevant across the different countries, and very specific, mostly country dependent information. In the present study, the summary results of the focus groups were used to give direction to the content of the intervention while very specific focus group results were applied to culturally adapt the intervention in every participating country. Program planners are advised to emphasize the use of specific focus groups results while preparing for cultural and local adaptation.

Although the literature acknowledges the necessity of multi-component community-based efforts to prevent childhood obesity, we recognize that the school setting still plays a very important role in the IDEFICS intervention as several intervention modules are situated at this level. It is known that schools can have intensive contact with children at a very young age and can reach children with a low(er) SES [57]. Furthermore, the combination of classroom education (module 5), physical activity (module 6) and physical education programs (module 7), changes in the school environment and policy (module 8 and 9) make schools a viable setting for providing obesity interventions in a cost-effective manner [16]. As the literature describes and as confirmed by 
our formative research, targeting only the school is not the ultimate solution but the role of the school in preventing childhood obesity must be conceptualized as an important part of the broader community intervention $[9,58]$.

Our formative research also demonstrated that, for both physical activity and dietary behaviors, the variability in overall findings was larger within than between countries. This finding provided the opportunity to develop an overall standardized intervention framework for eight participating countries but revealed the need for flexibility to adapt the intervention to the local needs. It should be stressed that the IDEFICS intervention dealt with the variability in local circumstances between and within countries by integrating the establishment of working groups at the community and the school level. This bottom-up approach increases the likelihood of program sustainability in the long term [55]. Furthermore, the IDEFICS intervention can be considered as a compromise between delivering a standardized intervention program and modifications of the program to fit with the local needs in all participating countries [55].

The present paper aimed to describe the developmental process of the community-based IDEFICS intervention, providing valuable information for the development of obesity preventive intervention strategies in multi-centre settings.

\section{Conclusions}

The IDEFICS project developed a community-based intervention program for the prevention of childhood obesity by following the intervention mapping heuristic. The intervention program is based on the socio-ecological approach and incorporated findings from formative research. The intervention targets both environmental and personal factors through the social contexts having an impact on young children. Findings from formative research provided the rationale for developing a general and standardized intervention framework. However, local and cultural adaptation was necessary to make the intervention feasible and to enhance deliverability in all participating countries, this way increasing the likelihood of program sustainability in the long term. The development of a multi-level and -behavioral intervention within a European context appeared to be a long process that needs to be done systematically. Sufficient time, human resources and finances need to be planned in advance to be able to develop an intervention that is evidence-based and culturally relevant.

\section{List of abbreviations used}

SES: socio-economic status; IDEFICS: Identification and prevention of Dietaryand lifestyle-induced health EFfects In Children and infants; IMP: intervention mapping protocol; TV: television; IPM: intervention program manager

\section{Acknowledgements and Funding}

This work was done as part of the IDEFICS Study and is published on behalf of its European Consortium (http://www.idefics.eu). We gratefully acknowledge the financial support of the European Community within the Sixth RTD Framework Programme Contract No. 016181 (FOOD).

\section{Author details}

${ }^{1}$ Department of Movement and Sport Sciences, Ghent University, Watersportlaan 2, Ghent 9000, Belgium. ${ }^{2}$ Department of Public Health, Ghent University, De Pintelaan 185, block A, Ghent 9000, Belgium. ${ }^{3}$ Research Foundation Flanders, Ghent University, Watersportlaan 2, 9000 Ghent, Belgium. ${ }^{4}$ Department of Pediatrics, The Queen Silivia Childrens' University Hospital, Göteborg University, Smörslottsgatan, 41685 Göteborg, Sweden. ${ }^{5}$ Department of Public Health and Community Medicine, Sahlgrenska Academy, Box 454, University of Gothenburg, 40530 Göteborg, Sweden. ${ }^{6}$ GENUD (Growth, Exercise, Nutrition and Development) Research Group, University School of Health Sciences, University of Zaragoza, Domingo Miral $\mathrm{s} / \mathrm{n}$, Zaragoza 50009, Spain. ${ }^{7}$ Institute of Food Sciences, Unit of Epidemiology and Population Genetics, National Research Council, Via Roma 52 AC, Avellino 83100, Italy. ${ }^{8}$ Department of Pediatrics, University of Pécs; Jozsef A. str. 7, H-7623 Pécs, Hungary. ${ }^{9}$ National Institute for Health Development, Hiiu 42, Tallinn 50410, Estonia. ${ }^{10}$ Research and Education Institute for Child Health, Attikis str. 8, Strovolos 2027, Cyprus. ${ }^{11}$ Bremen Institute for Prevention Research and Social Medicine (BIPS), University of Bremen, Achterstr. 30, Bremen 28359, Germany. ${ }^{12}$ Hochschule Coburg, University of Applied Sciences, Friedrich-Streib-Str. 2, 96450 Coburg, Germany.

\section{Authors' contributions}

All authors contributed to the development, implementation and evaluation of the IDEFICS intervention. All authors read and approved the final manuscript.

\section{Competing interests}

The authors declare that they have no competing interests. The information in this document reflects the author's view and is provided as it is.

Received: 29 October 2010 Accepted: 1 August 2011

Published: 1 August 2011

\section{References}

1. Branca F, Nikogosian T, Lobstein T: The Challenge of Obesity in the WHO European Region and the Strategies for Responses Copenhagen; 2007.

2. Lobstein T, Baur L, Uauy R: Obesity in children and young people: a crisis in public health. Obesity Reviews 2004, 5(Suppl 1):4-104.

3. Wang Y, Lobstein T: Worldwide trends in childhood overweight and obesity. International Journal of Pediatric Obesity 2006, 1:11-25.

4. Péneau S, Salanave B, Maillard-Teyssier L, Rolland-Cachera MF, Vergnaud AC, Mejean C, Czernichow S, Vol S, Tichet J, Castetbon K, Hercberg S: Prevalence of overweight in 6- to 15-year-old children in central/ western France from 1996 to 2006: trends toward stabilization. International Journal of Obesity 2009, 33:401-407.

5. Sundblom E, Petzold M, Rasmussen F, Callmer E, Lissner L: Childhood overweight and obesity prevalences levelling off in Stockholm but socioeconomic differences persist. International Journal of Obesity 2008, 32:1525-1530.

6. Reilly JJ: Descriptive epidemiology and health consequences of childhood obesity. Best Practice \& Research Clinical Endocrinology \& Metabolism 2005, 19:327-341.

7. Guo SS, Wu W, Chumlea WC, Roche AF: Predicting overweight and obesity in adulthood from body mass index values in childhood and adolescence. American Journal of Clinical Nutrition 2002, 76:653-658.

8. Nader PR, O'Brien M, Houts R, Bradley R, Belsky J, Crosnoe R, Friedman S, Mei Z, Susman EJ: Identifying risk for obesity in early childhood. Pediatrics 2006, 118:e594-e601.

9. Summerbell CD, Waters E, Edmunds LD, Kelly S, Brown T, Campbell KJ: Interventions for preventing obesity in children. Cochrane Database of Systematic Reviews 2005, CD001871.

10. Campbell KJ, Hesketh KD: Strategies which aim to positively impact on weight, physical activity, diet and sedentary behaviours in children from zero to five years. A systematic review of the literature. Obes Rev 2007, 8:327-338 
11. Hesketh KD, Campbell KJ: Interventions to prevent obesity in 0-5 year olds: an updated systematic review of the literature. Obesity (Silver Spring) 2010, 18(Suppl 1):S27-S35.

12. Sallis JF, Owen N, Fisher EB: Ecological models of health behavior. In Health Behavior and Health Education: Theory, Research, and Practice.. 4 edition. Edited by: Glanz K, Rimer BK, Viswanath K. San-Fransisco: JosseyBass; 2008:465-486.

13. Bartholomew LK, Parcel GS, Kok G, Gottlieb NH: Planning Health Promotion Programs: An Intervention Mapping Approach San Fransisco: Jossey-Bass; 2006.

14. Crawford D, Jeffery RW: Obesity Prevention and Public Health Oxford University Press; 2005.

15. Swinburn B: Obesity prevention in children and adolescents. Child Adolesc Psychiatr Clin N Am 2009, 18:209-223.

16. Sharma M: International school-based interventions for preventing obesity in children. Obes Rev 2007, 8:155-167.

17. De Henauw S, Verbestel V, Marild S, Barba G, Bammann K, Eiben G, Hebestreit A, lacoviello L, Keimer K, Konstabel K, Kovács E, Lissner L, Maes L, Molnár D, Moreno LA, Reisch L, Siani A, Tornaritis M, Williams G, Ahrens W, De Bourdeaudhuij I, Pigeot I: The IDEFICS Community Oriented Intervention Program. A new model for childhood obesity prevention in Europe? International Journal of Obesity 2011, 35(Suppl 1):S16-23.

18. Bammann K, Peplies J, Sjöström M, Lissner L, De Henauw S, Galli C, Lacoviello L, Krogh V, Mårild S, Pigeot I, Pitsiladis Y, Pohlabeln H, Reisch L, Siani A, Ahrens W: Assessment of diet, physical activity and biological, social and environmental factors in a multi-centre European project on diet- and lifestyle-related disorders in children (IDEFICS). Journal of Public Health 2006, 14(11):279-289.

19. Ahrens W, Bammann K, De Henauw S, Halford J, Palou A, Pigeot I, Siani A, Sjöström M: Understanding and preventing childhood obesity and related disorders-IDEFICS: a European multilevel epidemiological approach. Nutrition, Metabolism and Cardiovascular Diseases 2006, 16:302-308.

20. Brug J, Oenema A, Ferreira I: Theory, evidence and Intervention Mapping to improve behavior nutrition and physical activity interventions. Int $J$ Behav Nutr Phys Act 2005, 2:2

21. Michie S, Fixsen D, Grimshaw JM, Eccles MP: Specifying and reporting complex behaviour change interventions: the need for a scientific method. Implement Sci 2009, 4:40.

22. Haerens L, De Bourdeaudhuij, Barba G, Eiben G, Fernandez J, Hebestreit A, Kovács É, Lasn H, Regber S, Shiakou M, De Henauw S: Developing the IDEFICS community-based intervention program to enhance eating behaviors in 2- to 8-year-old children: findings from focus groups with children and parents. Health Education Research 2009, 24:381-393.

23. Haerens L, De Bourdeaudhuij I, Eiben G, Lauria F, Bel S, Keimer K, Kovács É, Lasn H, Regber S, Shiakou M, Maes L: Formative Research to Develop the IDEFICS Physical Activity Intervention Component: Findings From Focus Groups With Children and Parents. Journal of Physical Activity and Health 2010, 7:246-256.

24. Saunders RP, Evans MH, Joshi P: Developing a process-evaluation plan for assessing health promotion program implementation: a how-to guide. Health Promot Pract 2005, 6:134-147.

25. Dubois L, Girard M: Early determinants of overweight at 4.5 years in a population-based longitudinal study. Int J Obes (Lond) 2006, 30:610-617.

26. Shrewsbury $V$, Wardle J: Socioeconomic status and adiposity in childhood: a systematic review of cross-sectional studies 1990-2005. Obesity (Silver Spring) 2008, 16:275-284.

27. Semmler C, Ashcroft J, van Jaarsveld CH, Carnell S, Wardle J: Development of overweight in children in relation to parental weight and socioeconomic status. Obesity (Silver Spring) 2009, 17:814-820.

28. Rey-López JP, Vicente-Rodriguez G, Biosca M, Moreno LA: Sedentary behaviour and obesity development in children and adolescents. Nutrition, Metabolism and Cardiovascular Diseases 2008, 18:242-251.

29. Hills AP, King NA, Armstrong TP: The contribution of physical activity and sedentary behaviours to the growth and development of children and adolescents: implications for overweight and obesity. Sports Med 2007, 37:533-545

30. Mo-suwan L, Pongprapai S, Junjana C, Puetpaiboon A: Effects of a controlled trial of a school-based exercise program on the obesity indexes of preschool children. American Journal of Clinical Nutrition 1998, 68:1006-1011
31. Metallinos-Katsaras ES, Freedson PS, Fulton JE, Sherry B: The association between an objective measure of physical activity and weight status in preschoolers. Obesity 2007, 15:686-694.

32. Janz KF, Levy SM, Burns TL, Torner JC, Willing MC, Warren JJ: Fatness, physical activity, and television viewing in children during the adiposity rebound period: the lowa Bone Development Study. Preventive Medicine 2002, 35:563-571.

33. Moore LL, Gao D, Bradlee ML, Cupples LA, Sundarajan-Ramamurti A, Proctor MH, Hood MY, Singer MR, Ellison RC: Does early physical activity predict body fat change throughout childhood? Preventive Medicine 2003, 37:10-17.

34. Trost SG, Sirard JR, Dowda M, Pfeiffer KA, Pate RR: Physical activity in overweight and nonoverweight preschool children. International Journal of Obesity and Related Metabolic Disorders 2003, 27:834-839.

35. Monasta L, Batty GD, Cattaneo A, Lutje V, Ronfani L, van Lenthe FJ, Brug J: Early-life determinants of overweight and obesity: a review of systematic reviews. Obes Rev 2010.

36. Dennison BA, Erb TA, Jenkins PL: Television viewing and television in bedroom associated with overweight risk among low-income preschool children. Pediatrics 2002, 109:1028-1035.

37. Robinson TN: Television viewing and childhood obesity. Pediatr Clin North Am 2001, 48:1017-1025.

38. Reilly JJ, Armstrong J, Dorosty AR, Emmett PM, Ness A, Rogers I, Steer C, Sherriff A: Early life risk factors for obesity in childhood: cohort study. BMJ 2005, 330:1357.

39. Moreno LA, Rodriguez G: Dietary risk factors for development of childhood obesity. Curr Opin Clin Nutr Metab Care 2007, 10:336-341.

40. Leahy KE, Birch LL, Rolls BJ: Reducing the energy density of multiple meals decreases the energy intake of preschool-age children. Am J Clin Nutr 2008, 88:1459-1468.

41. Rolls BJ: The relationship between dietary energy density and energy intake. Physiol Behav 2009, 97:609-615.

42. Libuda L, Kersting M: Soft drinks and body weight development in childhood: is there a relationship? Curr Opin Clin Nutr Metab Care 2009, 12:596-600.

43. Muckelbauer R, Libuda L, Clausen K, Reinehr T, Kersting M: A simple dietary intervention in the school setting decreased incidence of overweight in children. Obes Facts 2009, 2:282-285.

44. Rolls BJ: Plenary Lecture 1: Dietary strategies for the prevention and treatment of obesity. Proc Nutr Soc 2010, 69:70-79.

45. Torres SJ, Nowson CA: Relationship between stress, eating behavior, and obesity. Nutrition 2007, 23:887-894.

46. Holmes ME, Ekkekakis P, Eisenmann JC: The physical activity, stress and metabolic syndrome triangle: a guide to unfamiliar territory for the obesity researcher. Obes Rev 2010, 11:492-507.

47. Koch FS, Sepa A, Ludvigsson J: Psychological stress and obesity. J Pediatr 2008, 153:839-844.

48. Golan M, Weizman A: Familial approach to the treatment of childhood obesity: conceptual mode. J Nutr Educ 2001, 33:102-107.

49. Lindsay AC, Sussner KM, Kim J, Gortmaker S: The role of parents in preventing childhood obesity. Future Child 2006, 16:169-186.

50. Lumeng JC, Somashekar D, Appugliese D, Kaciroti N, Corwyn RF, Bradley RH: Shorter sleep duration is associated with increased risk for being overweight at ages 9 to 12 years. Pediatrics 2007, 120:1020-1029.

51. Taveras EM, Rifas-Shiman SL, Oken E, Gunderson EP, Gillman MW: Short sleep duration in infancy and risk of childhood overweight. Arch Pediatr Adolesc Med 2008, 162:305-311.

52. Touchette E, Petit D, Tremblay RE, Boivin M, Falissard B, Genolini C, Montplaisir JY: Associations between sleep duration patterns and overweight/obesity at age 6. Sleep 2008, 31:1507-1514.

53. Landhuis CE, Poulton R, Welch D, Hancox RJ: Childhood sleep time and long-term risk for obesity: a 32-year prospective birth cohort study. Pediatrics 2008, 122:955-960.

54. National Association for Sport and Physical Education: Active start: a statement of physical activity guidelines for children birth to five years. Oxon Hill MD: AAHPERD Publications; 2002.

55. González Castro F, Barrera M Jr, Martinez CR Jr: The cultural adaptation of prevention interventions: resolving tensions between fidelity and fit. Preventive Science 2004, 5:41-45.

56. Ahrens W, Bammann K, Siani A, Buchecker K, De Henauw S, lacoviello L, Hebestreit A, Krogh V, Lissner L, Mårild S, Molnár D, Moreno LA, Pitsiladis Y, 
Reisch L, Tornaritis M, Veidebaum T, Pigeot I: The IDEFICS cohort: design, characteristics and participation in the baseline survey. International Journal of Obesity 2011, 35(Suppl 1):S3-15.

57. Story M, Kaphingst KM, French S: The role of schools in obesity prevention. Future Child 2006, 16:109-142.

58. Doak CM, Visscher TL, Renders CM, Seidell JC: The prevention of overweight and obesity in children and adolescents: a review of interventions and programmes. Obes Rev 2006, 7:111-136.

doi:10.1186/1479-5868-8-82

Cite this article as: Verbestel et al:: Using the intervention mapping protocol to develop a community-based intervention for the prevention of childhood obesity in a multi-centre European project: the IDEFICS intervention. International Journal of Behavioral Nutrition and Physical Activity 2011 8:82.

Submit your next manuscript to BioMed Central and take full advantage of:

- Convenient online submission

- Thorough peer review

- No space constraints or color figure charges

- Immediate publication on acceptance

- Inclusion in PubMed, CAS, Scopus and Google Scholar

- Research which is freely available for redistribution

Submit your manuscript at www.biomedcentral.com/submit 